\title{
A Theoretical Evaluation of Political and Legislative Strategies in Policy Development and Implementation
}

\author{
Sani Mustapha Kura, Adda Gana Bukar, Balu Bukar Abba \\ Ramat Polytechnic, Maiduguri, Department Of Social Services, P.M.B. 1070, Borno State, Nigeria. \\ Ramat Polytechnic, Maiduguri, Department Of Social Services, P.M.B. 1070, Borno State, Nigeria. \\ Ramat Polytechnic, Maiduguri, Department Of Social Services, P.M.B. 1070, Borno State, Nigeria.
}

\begin{abstract}
This paper attempts to explain political strategy and how policy practitioners develop and implement political resources in agency, community or legislative settings.

It further emphasizes the challenges political office holders encounter in the course of administrations which is not unconnected with the lack of blue print from the onset about how to develop and implement the much needed popular policies.

It also opined reasons why politicians and legislators fail in their responsibilities due to development and implementation of poor policies that are not people oriented which is notably common among third world countries most especially Nigeria leading to political and economic crisis.
\end{abstract}

\section{Introduction}

There is no generally accepted definition of politic however, politics can be seen in two perspectives i.e., traditional and modern view, the former view politics as mainly with the study or states or government or related institution while the latter sees politics as the struggle for power to make authoritative decisions for the whole society, Shaw and Pierce (1973).

Politics exists everywhere; it is all pervading and as old as human beings. Politics prevails in every sphere of life whether one likes or not, virtually, no one is completely beyond the reach of some kind of political system. A citizen encounters politics in the government of the country, town, school, political party, civil association, trade union and host of other organizations. Politics has always been created by human beings that gave birth to empires, nations, wars, revolutions, symbols, institutions, constitutions etc, it is a human venture centered in man and created by man, Mahajan (2008). Prior to the explanation of what political strategy meant, it will be helpful to define what "strategy" connotes. By strategy we mean, "Planned sequence of actions and verbal exchanges in a specific time frame to increase the likelihood that a proposal will be enacted". In this way we define political strategy as a planned sequence of actions and verbal exchanges that political practitioners implore in a specific time frame to increase the likelihood of enacting their political proposal or objectives.

Policy practitioners are faced with four unique challenges, this include firstly, to identify a political objectives that define what they want to achieve during specific period of time, that is to say, policy practitioners in a specific time frame to increase the likely hood of enacting their political proposal or objective. Policy practitioners are faced with lots of challenges, this include firstly, to identify a political objective that define what they want to achieve during specific period of time, that is to say, policy practitioners in imploring political, they have to establish or create a political proposal that would make them to achieve their target goal in specified time frame. Time frame is very crucial, in the sense that, the nature of the society change over time, here the dynamic nature of the society is a very determining factor of events and changes, hence of the society is a very determine factor of event and changes, henceforth political practitioner are mindful of this fact that whenever there is change in time frame as they envisage, the whole planned strategy will fail, that is why it is a challenge to political practitioners. Secondly, political or policy practitioners also do face a challenge in understanding the existing political realities that provide the context or starting point for developing strategy. This is very crucial in the sense that, until and unless the realities on ground are recognized, the entire strategy will not achieve its target proposal. Thirdly, policy practitioners faced with a challenge when they devise political strategy, they have to develop and implement strategy that identifies actions and discussions that will enable them to obtain their policy proposal or objective. A political strategy that fail to develop and implement existing political realities will have difficulty in achieving their policy objectives; and finally, policy practitioners need to revise their strategy should they find it to be ineffective, whether, because they made some miscalculations at the outset or due to changing events have rendered their original strategy obsolete, but due to non-professionalism on the side of some policy practitioners, they do not follow these steps in a neat progression. 


\section{How do policy practitioners use their power resources to develop-and implement political strategy in} Agency, Community or Legislative Settings?

In order to develop and implement political strategy, in Agency, Community or Legislative settings, policy practitioners have to establish some orienting objectives, hence to develop intelligent political strategy policy practitioners have to first answer the question, why am I participating in the political process?. This means, policy practitioners have to decide what side they are taking as well as how much and what kind of policy changes they seek, to answer this, policy practitioners should decide whether to choose or take either of the following positions:

1. An affirmative position

2. An amending position

3. A bystander position

4. A bystander position

These choices with regard to what position a policy practitioner should choose are very vital because they commit the strategist to certain obligations and risks. Political or policy practitioners who develop a political strategy have to devote a considerable time in research, discussions, meetings, negotiations and allow themselves to criticism form those who they engage, in this way their ideas or proposal will be exposed to a vigorous scrutiny, and the end result will guide the policy practitioners in taking a progressive steps. Obviously, due to exposure of the proposal to the people during deliberation, initiators who begin the strategy may affirm them (first position) because they initiate their own proposal or objectives while on the other hand, some people may decide to amend them (second position). Assume, e.g. that someone is generally in accord with another person's position but does not wish to devote or invest time in developing a proposal by amending the proposal during policy deliberations, this person can advance him/her preferences for specific changes.

In contrast, people sometimes assume a blocking or negative role to be a barrier so as to solve the enactment of an objectionable proposal, because it is easier in some aspect to block proposals than to develop them because oppositions need only pinpoint their flaws or errors which is very simple than developing them in first instance.

In this way, they block or oppose the initiatives of other (third position) these people in this category are takers, because blockers encounter risks of their own, however, they can be prepared to be "nay Sayers" who lack constructive alternatives and may be accused of opposing changes because they benefit from existing policies on ground.

Policy practitioners may sometimes assume or adopt no role (fourth position) that is, they remain bystander or 'aloof' from the deliberations that are associated with an issue, this may occur partly because they believe that they lack power to influence outcomes, partly, they want to save time or their scarce political resources for a future issue, perhaps, they believe that involvement in deliberations will require them to be hostile to one another or both sides in a controversy, or they can assume bystander so as to stay on the sidelines until they can assume a mediating role. This analysis usually prevails more in a legislative setting, some legislators may be reluctant to develop proposals just as they might not obstruct a proposal that had attracted widespread support. Legislators do also sometimes oppose objectives policies or develop proposals in the face of overwhelming odds, whether because they believe fundamental principles are at Stake or because they want to convince some segment of their constituency that will champion their interest.

A policy practitioner that uses their power resources to develop and implement political strategy in a Community setting often encounter the perennial question such as, do we need change, relatively major or incremental changes, this has to do with either a large or short term perspective which is also determined by time. However, this choice is often difficult to make. A policy practitioner may believe that major changes need to provide assistance to a given Community to revitalize an existing program, but the time frame will discourage the policy practitioner if at all the Community people need an urgent services. But fundamental changes are often not politically feasible and moreover, require relatively large investments of time and energy. Political realities importantly shape this choice if a considerable number of people oppose a specific initiative, e.g. policy practitioner may have to settle for relatively modest changes in existing policy; in some cases, policy practitioners have the modest objectives of sensitizing or educating people about a particular policy problem or issue because it is impossible to develop and enact policies of people that do not first believe that a problem exist.

Political strategy provide a method of actualizing power resource by combining and sequencing them into a patterned of actions and verbal exchanges. Skilful strategies can sometimes convert a seemingly hopeless situation into a more promising one by carefully analyzing the existing distribution of power and sentiment, by selecting a well considered strategy as well as revising strategy as condition warrant. However, these steps are not taken by policy practitioners neatly because they protect their interest at the detriment of the mass majority.

\section{THEORETICAL FRAMEWORK}


Every administration, military or civilian, has the responsibility of introducing welfare programmes for people through its policy statement designed by policy practitioners, especially in areas such as housing, health, education and the economic sector,(Aminu ,2002). However, in the real sense these policies are being formulated or made by the elite or the ruling class for their own interest as the Italian Sociologist Pareto and Mosca (1963), rightly argued in their theory called the Elite Theory. Elite Theory was first develop by pareto and Mosca, they both saw rule as inevitable and dismiss the possibility of a proletarian revolution leading to the establishment of a communist society because of the inevitability of elite rule, neither saw it as desirable that any attempt should be made to end it but rather, Pareto and Mosca agreed that the basis of elite rule was the superior personal qualities of those who make up the elite.

Pareto believe that elite possess more cunning or intelligence, while Mosca saw them as having more organizational ability since people were unequal, some will always have more ability than others, and will therefore occupy the elite position in the society.

Accordingly both theorists argued that apart from the personal qualities of the members, elite owes its power to its internal organization. In Mosca's word the power of the minority is irresistible as against each single individual in the majority's major decisions that affect societies are taken by the elite. Even in so-called democratic societies, this decision will usually reflect the concern of the elite rather than the wishers of the people. Elite theorist picture the majority as apathetic and unconcerned with the major issues of the day. The mass of the population is largely controlled and manipulated by the elite, passively, accepting the propaganda which justifies elite rule. Pareto argued that there are two types of governing elite, which he called "lion and fox" (following his mentor Machiavelli). He argued that lion achieve power because of their ability to take direct and incisive action, and, as their name suggest they tend to rule by force. Military dictator provides an example of this type of governing elite. Foxes by comparison rule by cunning and guile, by diplomatic, manipulation and wielding and dealing. Members of the governing elite owe their positions primarily to their personal qualities either lion-like or fox-like characteristics.

Going by this theory or postulations of the two, it is glaring clear that political strategy is geared towards the interest of policy practitioners who devise ways of developing and implementing political resources in either agency, community or in a legislative setting to their best interest and not to some greater extent the interest of the mass majority.

\section{Conclusion}

Conclusively, Oleary and Coplin have developed a simple scoring system to assess the distribution of power and sentiment with respect to an issue or proposal. This is done by scoring each member with respect to their position, so that the highest scoring member may eventually win, this approach is called force-field analysis. However, a single negative or positive score by a powerful participant can markedly decrease or increase the likelihood that a specific issue or proposal will be enacted, This approach of force field analysis may seem far-fetched, but it should be realized that this kind of analysis crude and imperfect as it may be, is sometimes used by politicians in legislative settings who keep numerical tallies to determine the prognosis for specific pieces of legislation. This is however, detrimental to the mass majority of the populace because a simple majority can lead to policy that is only favourable to them.

\footnotetext{
[1]. Aminu Y.C (2002): "Leading Issues in Economic Development and Social Welfare". Samarib Publishers.

[2]. Jansson, B.S. (1990): "Social Welfare Policy".

[3]. Pareto and Mosca (1963): "The Elite Theory" in Haralambus and Holborn Sociology Themes and Perspective.

[4]. Shaw and Pierce (1973): "Political Theory in the Principle of Political Sciences"

[5]. V.D. Mahajan (2008): "Political Theory in the Principle of Political Science".
} 